DOI: http://dx.doi.org/10.33387/jiko

\title{
IMPLEMENTASI WIRELESS SENSOR NETWORK (WSN) UNTUK MONITORING SMART FARMING PADA TANAMAN HIDROPONIK MENGGUNAKAN MIKROKONTROLLER WEMOS D1 MINI
}

\author{
Masdukil Makruf ${ }^{1)}$, Ainiyatus Sholehah'², Miftahul Walid ${ }^{3)}$ \\ ${ }^{1,2,3)} \mathrm{S} 1$ Informatika, Universitas Islam Madura \\ Email: ${ }^{1}$ masdukil.makruf@uim.ac.id, ${ }^{2}$ ainiyatussolehah96@gmail.com, ${ }^{3}$ miftah.walid@gmail.com
}

(Naskah masuk: 20 September 2019, diterima untuk diterbitkan: 30 Oktober 2019)

\begin{abstract}
ABSTRAK
Kemajuan infrastruktur properti bangunan semakin padat, terbukti dengan banyak berdirinya gedung-gedung yang dibangun membuat lahan untuk bercocok tanam semakin sempit. Tanaman hidroponik bisa dijadikan sebagai alternatif bercocok tanam dan dapat dikembangkan untuk wilayah padat bangunan seperti daerah perkotaan. Teknik penanaman pada tanaman hidroponik tidak membutuhkan media tanam yang luas seperti pada umumnya. Faktanya, cara pemeliharaanya saat ini masih manual seperti halnya memberi nutrisi, memantau status nutrisi, serta menjaga ketersediaan air pada tanaman hidroponik (Jalil;2017). Pemeliharaan secara manual dianggap kurang efisien, sehingga membutuhkan banyak waktu dan tenaga dalam mengaplikasikannya. Sistem monitoring secara realtime bisa menjadi solusi dalam perawatan tanaman hidroponik supaya lebih efisien. Sistem monitoring dengan sistem jaringan sensor nirkabel yang difungsikan untuk membaca kondisi terkini pada tanaman hidroponik memudahkan penanam sehingga tidak perlu melakukan observasi secara langsung (Gregory dkk;2018). Sistem monitoring pada Smart Farming menggunakan perangkat mikrokontroller Wemos D1 Mini untuk mengolah data dari sensor-sensor yang kemudian datanya dikirim ke firebase (realtimedatabase) melalui jaringan internet dan dilaporkan ke penanam secara realtime. Sensor yang digunakan pada sistem monitoring ini ialah sensor turbidity yang berfungsi membaca tingkat kekeruhan air yang tercampur nutrisi dan sensor DHT11 yang digunakan untuk mengukur suhu pada tanaman hidroponik.
\end{abstract}

Kata kunci: Hidroponik, Monitoring Sistem,WSN.

\section{WIRELESS SENSOR NETWORK (WSN) IMPLEMENTATION TO MONITOR SMART AGRICULTURE IN HYDROPONIC PLANTS USING WEMOS D1 MINI MICROCONTROLLER}

\begin{abstract}
The progress of building property infrastructure is increasingly dense, as evidenced by the many buildings that are built to make land for farming increasingly narrow. Hydroponic plants can be used as an alternative to farming and can be developed for dense building areas such as urban areas. The planting technique on hydroponic plants does not require a broad planting medium like in general. In fact, current maintenance methods are still manual, such as providing nutrition, monitoring nutritional status, and maintaining water availability in hydroponic plants (Jalil;2017). Manual maintenance is considered less efficient, so it requires a lot of time and effort in applying it. Realtime monitoring systems can be a solution in maintaining hydroponic plants to be more efficient. The monitoring system with a wireless sensor network system that is enabled to read the latest conditions on hydroponic plants makes it easy for growers so that they do not need to make direct observations (Gregory dkk;2018). The monitoring system in Smart Farming uses the Wemos D1 Mini microcontroller to process data from sensors which are then sent to the firebase (realtime-database) through the internet network and reported to the grower in real time. The sensor used in this monitoring system is the turbidity sensor which functions to read the turbidity level of water mixed with nutrients and the DHT11 sensor used to measure temperature in hydroponic plants.
\end{abstract}

Keywords: Hydroponic, Monitoring System, WSN.

\section{PENDAHULUAN}

Dewasa ini perkembangan permukiman dan pembangunan infrastruktur properti semakin padat, terbukti dengan banyaknya pengembang perumahan 
Masdukil Makruf, dkk, Implementasi Wireless Sensor Network (WSN) Untuk Monitoring Smart Farming Pada Tanaman Hidroponik Menggunakan Mikrokontroller Wemos D1 Mini

yang menjamur di daerah perkotaan bahkan hinggak ke pelosok desa. Hal ini memiliki dampak yang signifikan terhadap berkurangnya lahan yang tepat untuk bercocok tanam.

Tanaman Hidroponik dapat dijadikan alternatif bercocok tanam yang bisa dikembangkan untuk wilayah padat bangunan seperti daerah perkotaan (lingga;1984). Teknik penanaman hidroponik tidak membutuhkan media tanam yang luas seperti pada teknik penanaman pada umumnya. Teknik tanam jenis hidroponik walaupun mampu menjadi solusi untuk wilayah lahan terbatas, namun cara pemeliharaanya saat ini masih manual yaitu dengan mengandalkan tenaga manusia untuk melakukan perawatan seperti halnya memberi nutrisi, memantau status nutrisi, serta menjaga ketersediaan air pada bidang yang digunakan oleh tanaman hidroponik (jalil;2017).

Pemeliharaan tersebut dinilai kurang efisien, sehingga membutuhkan banyak waktu dan tenaga dalam mengaplikasikannya. Panelitian sebelumnya sudah dilakukan oleh (jalil;2017) yang melakukan penditeksian level air pada media tanam hidroponik berbasis Arduino uno dimana sistem yang dirancang adalah untuk memonitoring level air sehingga memudahkan petani dalam mengontrol ketersediaan air pada tanaman hidroponik. Jenis monitoring lainnya juga dilakukan oleh (Indriyani dkk;2017) dengan membuat sistem kontrol jarak jauh menggunakan jaringan internet yang memudahkan petani dalam melakukan monitoring kapanpun dan dimanapun.

Sistem monitoring secara realtime dianggap mampu menjadi solusi sehingga dalam perawatan tanaman hidroponik dapat lebih efisien. Sistem monitoring dengan memanfaatkan sistem jaringan sensor nirkabel atau biasa disebut Wireless Sensor Network (WSN) difungsikan untuk membaca kondisi tekini pada tanaman hidroponik memudahkan petani sehingga tidak perlu melakukan observasi secara langsung (Gregorio dkk;2018). Sistem Monitoring untuk menunjang sistem Smart Farming ini menggunakan device mikrokontroller Wemos D1 Mini yang difungsikan untuk mengolah data sensor dan dikirim melalui sistem firebase (realtimedatabase) melalui jaringan internet ke device android secara online. Adapun sensor yang digunakan pada sistem monitoring ini adalah sensor turbidity yang berfungsi untuk membaca tingkat kekeruhan air yang sudah tercampur nutrisi tanaman hidroponik, sensor DHT11 yang digunakan untuk mengukur suhu pada tanaman hidroponik dan mini pump digunakan untuk sirkulasi air ke talang hidroponik dengan tujuan air tetap terjaga kualitasnya.

\section{PENDAHULUAN}

\subsection{Sistem Hidroponik}

Sistem hidroponik (hydroponics) adalah teknik budidaya tanam yang tidak mengguanakan media tanah (Soil Culture). Termasuk model bercocok tanam menggunakan pot atau wadah lain yang menggunakan air atau bahan porous lainnya seperti kapas, pasir, kerikil maupun pecahan genting.

Dahulu, beberapa peneliti di laboratorium fisiologi tumbuhan sering berinteraksi dengan media tanam air sebagai alternatif bercocok tanam tanpa tanah. Sebagian orang menganggapnya sebagai aquakultur (menanam dalam air). uji coba ini ternyata berhasil sehingga banyak ahli-ahli agronomi mengembangkan metode tersebut (lingga;1984).

\subsection{Wireless Sensor Network (WSN)}

Wireless Sensor Network (WSN) atau dalam bahasa Indonesia dikenal dengan jaringan sensor nirkabel merupakan jaringan yang menghubungkan perangkat-perangkat seperti sensor node, dan router. Perangkat ini mampu terhubung secara ad-hoc dan mendukung multi-hop communications. ad-hoc diistilahkan pada kemampuan perangkat untuk berkomunikasi satu sama lain secara langsung tanpa memerlukan infrastruktur jaringan terpusat. Sedangkan multi-hop merujuk pada system komunikasi yang melibatkan perangkat intermediate, multihop melibatkan perangkat yang dijadikan antara seperti router untuk meneruskan sebuah paket dari satu titik ke titik yang lain dalam sebuah jaringan.

WSN pada umumnya diimplementasikan untuk komunikasi data skala kecil yang digunakan untuk mengirim data hasil diteksi sensor untuk diolah kembali (Edgar dkk;2003).

\subsection{Mikrokontroller Wemos D1 Mini}

Mikrokontroller Wemos D1 Mini merupakan modul perangkat embedded system yang fungsinya hampir sama dengan arduino khususnya untuk mendukung konsep IoT (Internet of Things). Wemos D1 Mini mampu berjalan secara stand-alone, tanpa membutuhkan mikrokontroller khusus sebagai pengontrol atau pengendali pada rangkaian elektronik disebabkan Wemos D1 mini pada embedded sistemnya sudah dilengkapi dengan Central Processing Unit (CPU) (Putri;2017).

Pada modul Wemos D1 mini dilengkapi dengan PIN digital dan analog, salah satu input output pada modul wemos d1 yang paling dikenal adalah pin digital, walaupun pada dasarnya pin analog juga memiliki fungsi yang sama. Pin tersebut dapat dikonfigurasikan secara input maupun output.

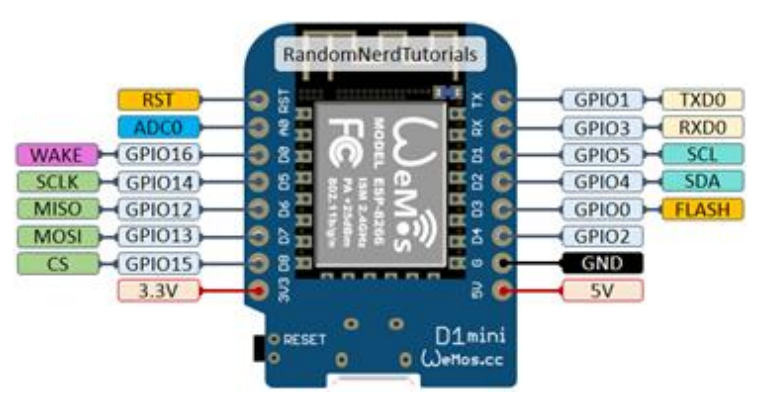

Gambar 1. Board Wemos D1 mini 
Masdukil Makruf, dkk, Implementasi Wireless Sensor Network (WSN) Untuk Monitoring Smart Farming Pada Tanaman Hidroponik Menggunakan Mikrokontroller Wemos D1 Mini

Perangkat Wemos dilengkapi dengan 2 buah chipset yang difungsikan sebagai otak kerja diantaranya:

\section{Chipset ESP8266}

ESP8266 adalah sebuah chip yang memiliki fitur koneksi wireless yang mendukung protocol TCP/IP. Dengan modul ini, mikrokontroler dapat terhubung kedalam jaringan wireless dan membuat koneksi TCP/IP cukup dengan perintah yang sangat sederhana. Dengan teknologi clock $80 \mathrm{MHz}$ perangkat ini dibekali dengan RAM Eksternal dengan kapasitas 4 Mega Byte dan mendukung format IEEE 802.11 $\mathrm{a} / \mathrm{b} / \mathrm{g} / \mathrm{n}$ sehingga dengan mudah melakukan koneksi terhadap jaringan wifi konvensional (Reddy;2017).

2. Chipset CH340

CH340 merupakan chipset yang memiliki fungsi mengubah USB menjadi serial interface, contohnya adalah aplikasi converter ke Infrared Data Association (IDA) atau USB converter ke perangkat Printer. Dalam mode serial interface, CH340 mengirimkan sinyal komunikasi seperti yang digunakan modem pada umumnya. CH340 didesain untuk merubah perangkat serial interface umum untuk berhubungan dengan port USB secara langsung (Utomo;2018).

\subsection{Sensor Kekeruhan (Turbidity)}

Keruh yang sering terjadi akibat air yang sering bergerak merupakan suatu hal yang biasa terjadi, bahkan dapat dijadikan sebagai sifat air yang mudah melarutkan benda-benda yang ada disekelilingnya. Sifat air yang satu ini paling susah dilakukan analisis, dikarenakan kekeruhan merupakan sifat optik pada air. Sensor kekeruhan atau biasa dikenal dengan turbidity biasa digunakan untuk mengukur jumlah atau massa partikel padat yang tercampur pada air. Sensor turbidity inilah yang akan mengirimkan data kepada mikrokontroller Wemos D1 (Patrick dkk;2011). Sensor turbidity ditunjukkan pada Gambar 2.

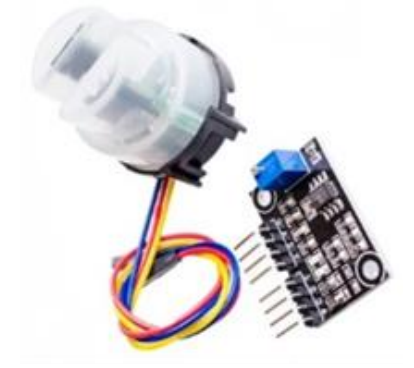

Gambar 2. Modul Sensor Turbidity

\subsection{Sensor Suhu DHT11}

Device sensor yang digunakan untuk mendeteksi suhu adalah DHT11 yang lumrah diaplikasikan untuk mengukur tingkat kelembaban udara disekitarnya. Sensor ini dapat difungsikan juga menggunakan mikrokontroller Arduiono dan
Wemos D1 mini. Sensor DHT11 memiliki tingkat stabilitas terbaik dengan tambahan fitur kalibrasi yang akurat. Sensor suhu ini termasuk sensor yang memiliki kualitas terbaik, dinilai dari waktu pada saat melakukan respon, proses membaca data yang sangat cepat, serta kemampuannya menjadi antiinterference detektor. Diameter bisa dbilaang sangat kecil, kendati demikian, ia mempunyai kemampuan transmisi atau jangkauan sinyal sampai dengan luas 20 meter (Saptadi;2014).

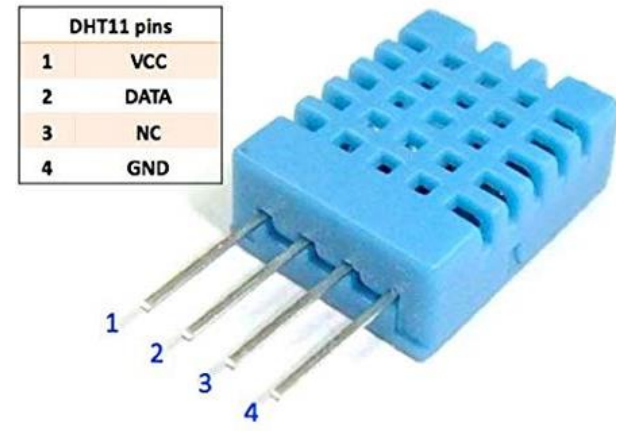

Gambar 3. Sensor Suhu DHT11

\subsection{Firebase (Realtime-Database)}

Firebase adalah salah satu dari beberapa jumlah penyedia layanan Mobile Backend as a Service (mBaaS) yang paling populer digunakan oleh para pengembang software mobile. Firebase ini diprakarsai oleh perusahaan software online terbesar yaitu Google yang memiliki visi dan misi untuk memudahkan para pengembang aplikasi mobile dalam memanfaatkan fitur-fitur firebase versi mutakhir. Teradapat beberapa layanan yang ditawarkan oleh firebase. Namun, yang digunakan pada penelitian ini adalah fitur Realtime-database. Fitur realtime database memungkinkan aplikasi yang dikembangkan dapat diakses secara langsung oleh end user. Kelebihan lainnya, realtime-database mampu menyimpan data secara lokal pada saat tidak ada akses internet, kemudian mampu melakukan sinkronisasi data secara otomatis setelah mendapatkan akses internet. Contoh penggunaan fitur ini, telah digunakan pada aplikasi popular seperti WhatsApp dan Line (Darrow;2019).

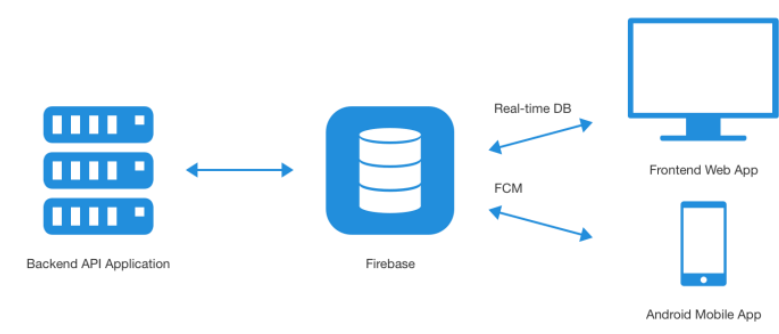

Gambar 3. Mikanisme Re،

\section{METODE PENELI', ....}

Gambar 1. Board Wemos D1 mini

Pada penelitian ini, ada beberapa tahapan yang dilakukan didasarkan pada tiga hal yaitu, 
Masdukil Makruf, dkk, Implementasi Wireless Sensor Network (WSN) Untuk Monitoring Smart Farming Pada Tanaman Hidroponik Menggunakan Mikrokontroller Wemos D1 Mini

perancangan prototype, uji coba sistem, dan analisa hasil. Secara umum tahapan perancangan sistem monitoring ini dilihat pada gambar 4 .

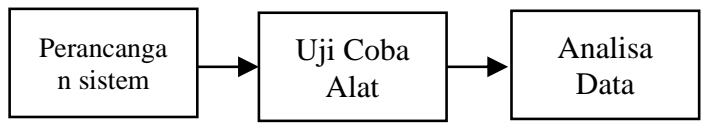

Gambar 4. Block Diagram Penelitian

\subsection{Perancangan Prototype Device}

Tahap awal dalam penelitian ini yang dilakukan adalah merancangan prototype untuk menunjang sistem monitoring tanaman hidroponik. Ada dua macam prototype yang hendak dibuat yaitu perancangan sensor turbidity yang memiliki fungsi untuk mengecek kondisi kekeruhan air dan perancangan sensor DHT11 yang memiliki fungsi untuk mengetahui kondisi suhu pada tanaman hidroponik. Kedua model perancangan tersebut berfungsi sebagai alat input pada mikrokontroller Wemos D1 [6].

1. Perancangan Sensor Turbidity.

Model perancangan prototype untuk menditeksi kekeruhan pada rangkaian sensor turbidity terhadap kekeruhan air, ditunjukkan pada Gambar 5.

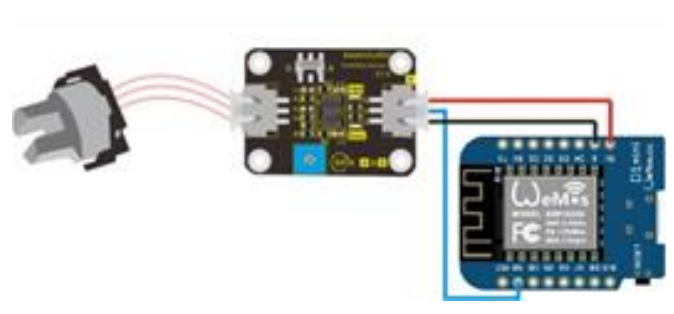

Gambar 5. Rangkaian Sensor Turbidity dengan Wemos Berikut ini adalah keterangan pin yang digunakan pada sensor turbidity dan mikrokontroller Wemos D1 Mini, ditunjukkan pada Tabel 1.

Tabel1. Keterangan Penggunaan PIN pada Sensor Turbidity dan mikrokontroller Wemos D1 Mini

\begin{tabular}{|c|c|}
\hline Pin Turbidity & Pin Wemos Dl mini \\
\hline VCC & $5 \mathrm{~V}$ \\
\hline$G N D$ & $G N D$ \\
\hline$O U T$ & $A O$ \\
\hline
\end{tabular}

2. Rangkaian sensor DHT11

Model perancangan prototype untuk menditeksi suhu pada rangkaian sensor DHT11 kondisi lingkungan tanaman hidroponik, ditunjukkan pada gambar 6 .

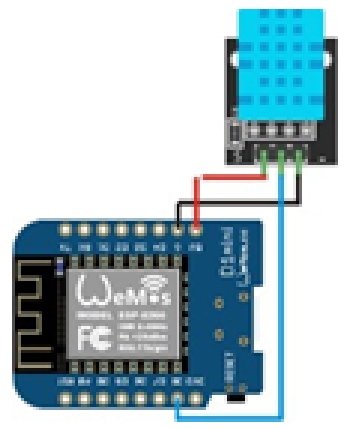

Gambar 6. Model Rangkaian Sensor DHT11

Berikut ini adalah keterangan pin yang digunakan pada sensor DHT11 dan mikrokontroller Wemos D1 Mini, ditunjukkan pada tabel 2 .

Tabel2. Keterangan Penggunaan PIN pada Sensor DHT11 dan Mikrokontroller Wemos D1 Mini

\begin{tabular}{|c|c|}
\hline Pin DHT11 & Pin Wemos D1 mini \\
\hline$V C C$ & $5 \mathrm{~V}$ \\
\hline$G N D$ & $G N D$ \\
\hline OUT & $D 8$ \\
\hline
\end{tabular}

\subsection{Perancangan Block Diagram System}

Perancangan block diagram system yang tergambar pada Gambar 7 berikut ini menjelaskan apabila sensor turbidity menditeksi perubahan pada kondisi air, dan sensor DHT11 menditeksi perubahan suhu pada sekitar tanaman hidroponik, maka kedua sensor tersebut secara otomatis akan mengirimkan nilai kepada mikrokontroller Wemos D1 mini yang sudah terhubung pada internet melalui modul modem yang dilengkapi dengan jaringan internet. Data yang dihasilkan oleh kedua sensor tersebut akan dikirimkan ke realtime-database pada firebase untuk dikelola dan disampaikan ke end user [11].

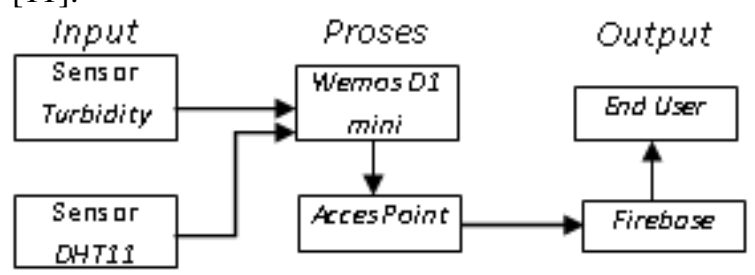

Gambar 7. Block Diagram Sensor turbidity dan Wemos D1 mini

\subsection{Flowchart Koneksi mikrokontroller Wemos ke Router dan Wemos ke Firebase}

Berikut ini adalah diagram alur koneksi Wemos D1 ke Router dan koneksi Wemos ke Firebase. Alur sistem kerja wemos D1 ke router dan ke firebase yaitu dimulai dengan inisialisai perangkat, kemudian wemos akan menghubungkan perangkat pada router dan menentukan SSID yang akan digunakan dan memasukkan password (apabila dibutuhkan) agar mendapatkan akses internet. Setelah wemos mendapatkan akses internet, wemos akan menghubungkan pada firebase (real-time database) dengan mengatur server firebase dan kode authentication agar mendapatkan akses langsung ke firebase. Kemudian data yang dikirim secara realtime ke database pada firebase akan diambil untuk ditampilkan pada aplikasi yang dijalankan 
Masdukil Makruf, dkk, Implementasi Wireless Sensor Network (WSN) Untuk Monitoring Smart Farming Pada Tanaman Hidroponik Menggunakan Mikrokontroller Wemos D1 Mini

pada platform android pada end user. Dengan begitu, user dapat mengontrol secara realtime kondisi terkini yang terjadi pada tanaman hidroponik. Alur sistem diatas digambarkan pada alur diagram yang digambarkan pada gambar 8 berikut ini.

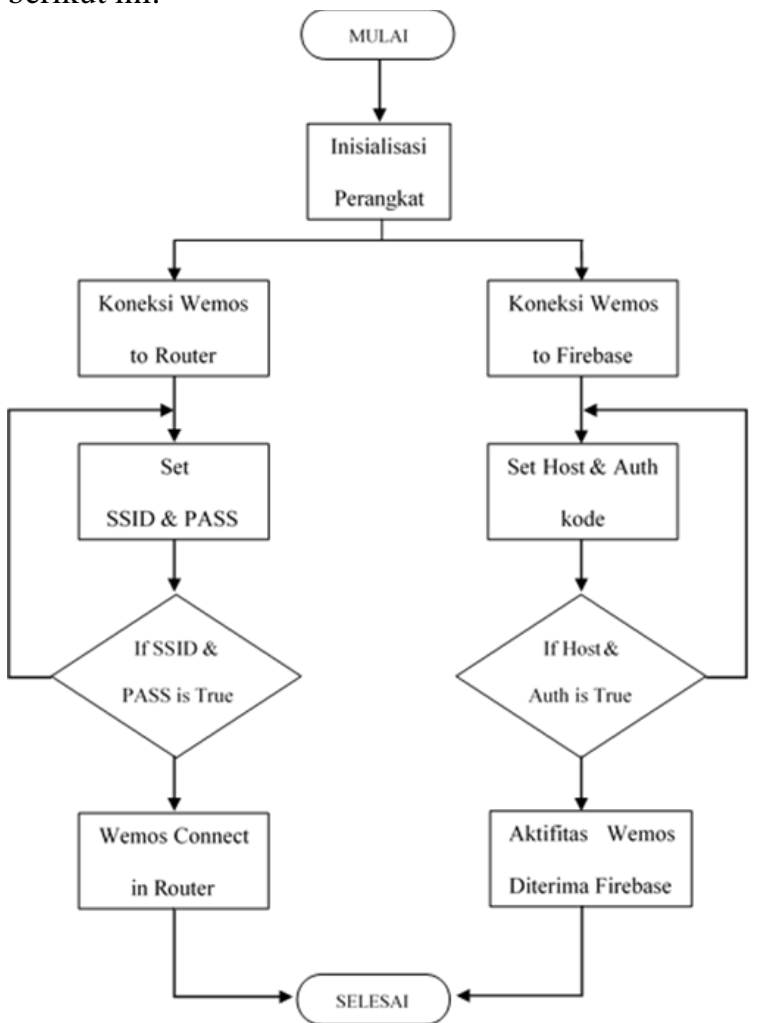

Gambar 8. Diagram Alir Koneksi Wemos ke Router dan Firebase

\subsection{Flowchart Sistem Monitoring Tanaman Hidro-ponik}

Setelah membahas alur koneksi Wemos ke Firebase, tahap selanjutnya adalah proses sistem monitoring yang dibuat, yaitu dimulai dari DHT11 dan sensor turbidity yang akan mengirimkan hasil penditeksian berupa nilai yang dikirim melalui koneksi internet ke realtime-database yang ada pada firebase. Setelah data terekam pada firebase, maka data tersebut dapat dipanggil melalui Aplication Programming Interface (API) yang disediakan oleh firebase yang nantinya dapat dijadikan sebagai jalur akses untuk dapat memanggil data yang telah dikirim oleh sensor turbidity dan sensor DHT11 sehingga dapat divisualisasikan kedalam Interface aplikasi pada smartphone android.

Data yang sudah berhasil dipanggil ke interface android kemudian diolah dan dibagi kedalam kategori-kategori secara otomatis yang telah ditentukan sehingga menghasilkan informasi sesuai kondisi yang terjadi pada lingkungan tanaman hidroponik. Dengan begitu, end user dapat mengetahui kondisi terkini pada tanaman hidroponik dengan menggunakan sistem monitoring ini. Adapun alur sistem monitoring digambarkan pada gambar flowchart berikut ini:

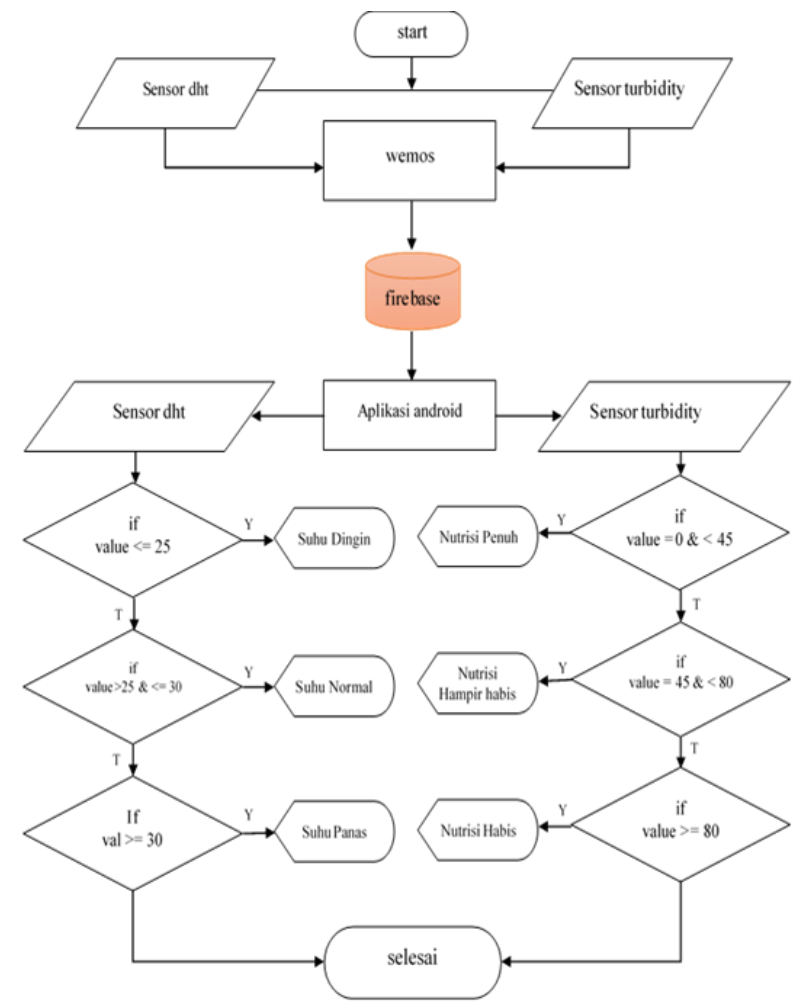

Gambar 9. Flowchat Koneksi Firebase dengan End User

\subsection{Tahap Implementasi Prototype Miniatur Tanaman Hidroponik}

Untuk dapat melakukan uji coba sistem monitoring smart farming terhadap tanaman hidroponik menggunakan Mikrokontroler Wemos D1 Mini perlu dibuat rancangan miniatur untuk melakukan ujicoba kinerja sistem monitoring ini. Prototype ini terdiri dari sensor turbidity, sersor DHT11, dan mikrokontroller Wemos D1 mini, mini pump, pipa air untuk tempat media air, dan koneksi wireless untuk koneksi ke firebase. Adapun miniatur yang telah dibuat ditunjukkan pada Gambar 10.

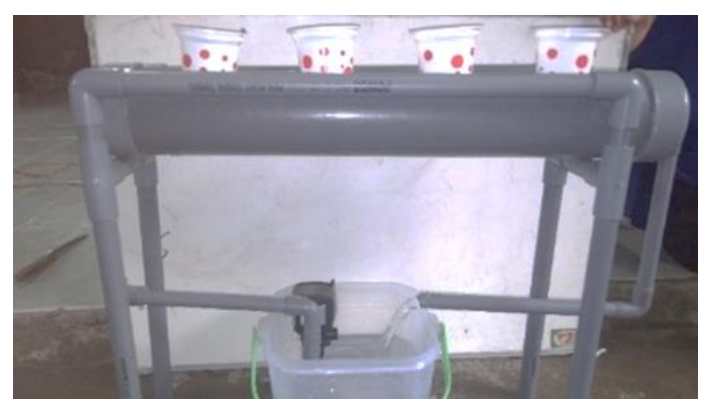

Gambar 10. Miniatur System Monitoring Smart Farming Pada Tanaman Hidriponik

\section{HASIL DAN PEMBAHASAN}


Masdukil Makruf, dkk, Implementasi Wireless Sensor Network (WSN) Untuk Monitoring Smart Farming Pada Tanaman Hidroponik Menggunakan Mikrokontroller Wemos D1 Mini

Sistem monitoring smart farming pada tanaman hidroponik ini dibuat secara miniatur untuk memudahkan peneliti dalam melakukan eksperimen. Sistem smart farming yang dibuat dalam bentuk miniatur sudah sukses berjalan seperi yang diinginkan pada tahapan penelitian ini.

Setelah berhasil merancangan prototype miniatur sistem monitoring untuk smart farming pada tanaman hidroponik ini, dapat dilakukan impelementasi dan pengujian sistem sehingga dapat diketahui performa pada prototype yang sudah dibuat. Ada beberapa hal yang akan dibahas pada penelitian ini.

\subsection{Implementasi Sistem}

Prinsip kerja dalam implementasi sistem monitoring smart farming pada tanaman hidroponik menggunakan mikrokontroller Wemos D1 mini dan menggunakan interface android telah diilustrasikan pada gambar 7. Prinsip kerjanya adalah air yang berada dalam penampungan air akan dipompa oleh mini pump ke atas melalui pipa sehingga air tersebut melewati semua akar pada tanaman yang akan ditanam kemudian air tersebut mengalir kebawah menuju penampungan air kembali. Proses ini terus berulang selama air dalam wadah penampungan masih tersedia. Dalam sistem monitoring ini terdapat dua sensor utama yang digunakan untuk sumber data monitoring yaitu sensor turbidity dan sensor DHT11. Sensor turbidity difungsikan sebagai alat untuk mendeteksi kandungan nutrisi yang tercampur pada air dengan melihat kadar kekeruhan air, sedangkan sensor DHT11 difungsikan sebagai pendeteksi kondisi suhu atau cuaca pada area sekitar tanaman hidroponik. Hasil dari data pantauan akan ditampilkan pada aplikasi android yang sebelumnya sudah dikirim oleh Wemos D1 mini ke firebase.

\subsection{Pengujian Sensor Turbidity}

Sensor turbinity memiliki pin analog yang difungsikan untuk mengirimkan sinyal tegangan. Sinyal tersebut akan dikonversi menjadi nilai-nilai integer oleh Wemos D1 mini sehingga sensor turbidity dapat mengirimkan data sesuai dengan hasil diteksi yang dilakukan secara otomatis oleh sensor tersebut. Pengujian sensor turbidity dapat dilihat pada gambar 11 dibawah ini.

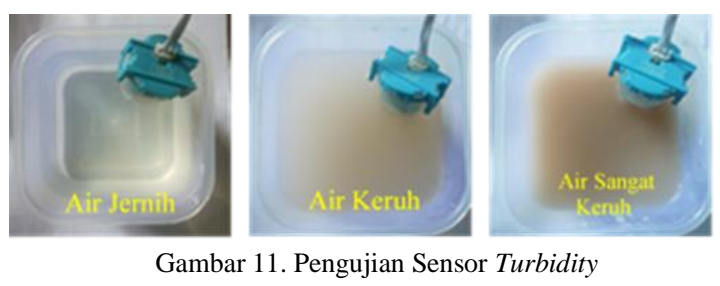

Pengujian sensor turbidity seperti yang terlihat pada gambar 11 diatas menggunakan 3 wadah, masing-masing berisikan air yang berbeda. Ada air jernih, air keruh, dan air yang sangat keruh. Hasil uji coba tersebut langsung ditampilkan pada aplikasi android setelah sebelumnya dikirim ke firebase oleh Mikrokontroler Wemos.

Untuk hasil pengujian turbidity menghasilkan data yang dikirim dari sensor ditunjukkan pada table 3 berikut ini:

Tabel3. Tabel Range Tingkat kekeruhan dalam air berdasarka uji

\begin{tabular}{|c|c|c|c|}
\hline Air & $\begin{array}{c}\text { Nilai } \\
\text { Sesor }\end{array}$ & If & Nutrisi \\
\hline Jernih & 4 & $\begin{array}{c}>=0 \& \\
<15\end{array}$ & Habis \\
\hline Keruh & 51 & $\begin{array}{c}>15 \& \\
<80\end{array}$ & Hampir abis \\
\hline $\begin{array}{c}\text { Sangant } \\
\text { keruh }\end{array}$ & 91 & $>80$ & Full \\
\hline
\end{tabular}

Berdasarkan tabel 3 diatas menunjukkan bahwa hasil uji coba pada gambar 11 sensor turbidity mengirimkan angka 4 dimana angka tersebut berada pada range 0 - 15 yang mana range tersebut tergolong kategori air jernih dalam artian jika air terditeksi jernih pada tanaman hidroponik menunjukkan bahwa nutrisi yang dicampurkan pada air sudah habis. Uji coba selanjutnya pada gambar 11 menunjukkan angka 51, dimana angka tersebut berada pada range 15 - 80 yang mana range tersebut tergolong air keruh namun tidak begitu padat. Angka tersebut menunjukkan jika Nutrisi yang ada sudah mulai berkurang dan bisa dikatakan hampir habis. Kemudian pada pengujian selanjutnya pada gambar 11 menunjukkan angka 91 dimana angka tersebut berada pada range diatas angka 80, sehingga dimaksudkan jika nilai yang dikirim oleh sensor turbidity diatas 80 menunjukkan kondisi air sangat keruh dengan kata lain nutrisi yang tercampur dalam air pada tanaman hidroponik dalam konsisi penuh.

\subsection{Pengujian Sensor DHT11}

Pengujian untuk Sensor DHT11 difungsikan untuk mengetahu suhu yang ada pada tanaman hidroponik. Sensor DHT11 dapat mangirimkan sinyal data yang dikirim ke Wemos. Hasil pengujian sensor DHT11 dapat dilihat pada gambar 12 dibawah ini:

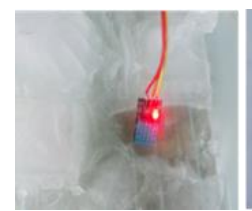

(a)

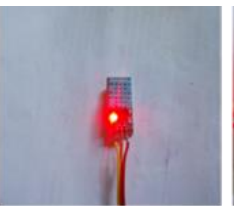

(b)

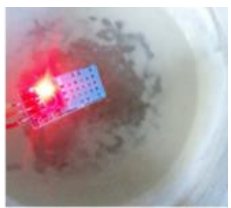

(b)
Gambar 12. a) Kondisi sensor pada saat suhu dingain, b) kondisi sensor pada saat suhu sedang, c) kondisi sensor saat pada suhu panas.

Pengujian sensor DHT11 menggunakan tiga sampel kondisi suhu yaitu dicoba pada suhu dingin, suhu normal, dan suhu panas. Untuk menguji sensor pada suhu dingin, sensor diletakkan diatas wadah yang berisikan potongan es batu, untuk menguji 
pada suhu normal sensor diletakkan ditempat biasa, dan untuk kondisi panas sensor diletakkan diatas wadah yang berisikan air panas. Uji coba ini bertujuan untuk mengambil sampel data pada suhu kondisi dingin, normal, dan panas.

Untuk hasil pengujian DHT11 menghasilkan data yang dikirim dari sensor ditunjukkan pada table 4 berikut ini:

Tabel4. Data hasil uji coba diteksi suhu pada sensor DHT11

\begin{tabular}{|c|c|c|c|}
\hline Suhu & $\begin{array}{c}\text { Nilai } \\
\text { Sesor }\end{array}$ & If & Nutrisi \\
\hline Dingin & 22 & $>=0 \&<=25$ & Dingin \\
\hline Normal & 30 & $>25 \&<=30$ & Normal \\
\hline Panas & 37 & $>30$ & Panas \\
\hline
\end{tabular}

Berdasarkan hasil data sensor yang ditunjukan pada tabel 4 diatas menunjukkan hasil uji coba pada gambar 12. Poin (a) pada gambar 12 menunjukkan bahwa sensor DHT11 diletakkan pada wadah berisikan potongan es, sehingga nilai yang dikirim oleh sensor adalah angka 22, dimana angka tersebut termasuk pada range $0-25$ yang mana range ini masih dikategorikan suhu dingin. Poin (b) pada gambar 12 menunjukkan bahwa sensor DHT11 diletakkan pada suhu sedang, sehingga nilai yang dikirim oleh sensor adalah angka 30, dimana angka tersebut termasuk pada range 25 - 30 yang mana range ini masih dikategorikan suhu sedang atau normal. Sedangkan pada poin (c) pada gambar 12 menunjukkan bahwa sensor DHT11 diletakkan pada suhu wadah berisikan air panas, sehingga nilai yang dikirim oleh sensor adalah angka 37, dimana angka ditas 30 dianggap suhu panas.

\subsection{Pengujian Interface End User}

Setelah interface end user dalam hal berupa aplikasi pada smart phone android yang digunakan sebagai interface komunikasi sensor dengan end user, perlu diuji sehingga sistem monitoring ini dapat berjalan sesuai keinginan. Interface android memiliki fungsi sebagai media pelaporan kepada end user untuk mengetahui kondisi terkini yang terjadi pada tanaman hedroponik yang dideteksi langsung oleh sensor turbidity dan sensor DTH11 secara realtime. Nilai sensor yang terangkum pada tabel 3 dan 4 diatas akan ditampilkan pada interface aplikasi android yang ditunjukkan pada gambar 13 berikut ini.

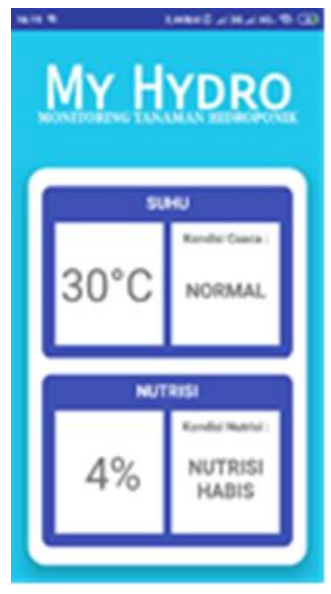

Gambar 13. Contoh tampilan user interface android pada end user

\section{KESIMPULAN}

Berdasarkan pengujian yang telah dilakukan, dapat dikatakan berhasil merancang wireless sensor network (WSN) untuk monitoring smart farming pada tanaman hidroponik berfungsi sesuai harapan. Hasil dari uji coba menyimpulkan bahwa nilai data sensor tidak dapat konstan pada nilai tertentu, melainkan angka yang dihasilkan hanya berada pada range yang ditentukan. Untuk pengembangan system selanjutnya dapat ditambahkan sistem kontrol pada pengisian nutrisi secara otomatis dengan menambahkan beberapa sensor, kemudian lakukanlah pengujian pada tingkat kekeruhan dimana nantinya dapat membedakan antara air keruh yang diakibatkan nutrisi atau air yang tercampur debu atau kotoran yang tentunya memiliki yang signifikan untuk perkembangan tanaman hidroponik.

\section{DAFTAR PUSTAKA}

Abdul Jalil , 2017, "Sistem Kontrol Deteksi Level Air Pada Media Tanam Hidroponik Berbasis Arduino Uno," Jurnal IT.

Gregorio TG, Victoria MS, Dkk, "Wireless Sensor Network for Monitoring Physical Variables Applied to Green Technology (IoT Green Technology)," European Journal of Electrical and Computer Engineering, vol. 2, no. 2, February 2018.

Pinus Lingga. 1984. Hindroponik ; Bercocok Tanam Tanpa Tanah. Jakarta: Penebar Swadaya.

Indriyani, T., \& Ruswiansari, M. Sugiono. 2017. "Kontrol Jarak Jauh Sistem Irigasi Sawah Berbasis Internet Of Things ( IoT )," INTEGER, vol. 2.

Jr Edgar and H Callaway. 2003. Wireless Sensor Networks: Architectures and Protocols. Boca Raton: AUERBACH.

Mustika Dian Putri. 2017. "MENGENAL WEMOS D1 MINI DALAM DUNIA IOT," ILMUTI ORG.

KPS Reddy, 2017 "Implementation of IOTwith Esp8266Part I -Creating A Prototype," JSRST, vol. 3 , no. 1

Deny Setyo Utomo. 2018. PRODUCT PRICE DISPLAY USING WEMOS. Surabaya: Stikom.

dkk Patrick P. Rasmussen. 2011. Guidelines and Procedures for Computing Time-Series Suspended-Sediment Concentrations and Loads from In-Stream Turbidity-Sensor and Streamflow Data. Virginia: USGS.

Arief Hendra Saptadi. 2014. "Perbandingan Akurasi Pengukuran Suhu dan Kelembaban Antara Sensor DTH11 dan DHT22Studi 
Masdukil Makruf, dkk, Implementasi Wireless Sensor Network (WSN) Untuk Monitoring Smart Farming Pada Tanaman Hidroponik Menggunakan Mikrokontroller Wemos D1 Mini

Komparatifpada PlatformATMEL AVR dan Arduino," Jurnal Infotel, vol. 6, no. 2,

Barb Darrow, "Firebase Secures Its Real-Time Back-end Service," p. gigaom.com, Diakses Tanggal 20 Nov 2019. 